\title{
A Comparative Study among Three Techniques of General Anesthesia for Ultrasound-Guided Transrectal Prostate Biopsy
}

\author{
Ricardo Antônio Guimarães Barbosa, TSA 1, Camerine Domingues da Silva 2, Mary Yumi Takei Torniziello 2, \\ Luciana Mendes de Olivera Cerri ${ }^{3}$, Maria José Carvalho Carmona, TSA ${ }^{4}$, Luiz Marcelo Sá Malbouisson, TSA ${ }^{5}$
}

\begin{abstract}
Summary: Barbosa RAG, Silva CD, Torniziello MYT, Cerri LMO, Carmona MJC, Malbouisson LMS - A Comparative Study among Three Techniques of General Anesthesia for Ultrasound-Guided Transrectal Prostate Biopsy.
\end{abstract}

Background and objectives: Ultrasound-guided transrectal prostate biopsy is a reference in the diagnosis of prostate neoplasias. The higher the number of samples, the greater is the pain and discomfort. The objective of this study was to compare three anesthetic techniques in this group of patients.

Methods: Forty-five patients were included in this study. Patients were divided into three groups: 1 - Propofol; 2 - Propofol + Prostatic Plexus Block; 3 - Propofol + Fentanyl. Patients were monitored with non-invasive blood pressure, continuous electrocardioscopy, pulse oximetry $\left(\mathrm{SpO}_{2}\right)$, and Bispectral Index. Patients did not receive pre-anesthetic medication. Intraoperative and postoperative hemodynamic parameters, intraoperative bispectral index, and postoperative visual analogue scale (VAS) and the use of dypirone to treat postoperative pain were evaluated.

Results: A significant difference among the three groups was not observed for: anthropometric parameters, amount of propofol, number of fragments, and duration of the exam. Hemodynamic parameters and $\mathrm{SpO}_{2}$ presented similar behavior in all three groups. In group 1 , the pain evaluated by the VAS was more severe and required more dypirone than in the other groups.

Conclusions: Sedation with propofol alone for biopsy is associated with greater postoperative pain and discomfort than in prostatic plexus block or systemic fentanyl. Besides hypnosis, intraoperative analgesia is required to guarantee postoperative comfort.

Keywords: ANESTHESIA, General; ANESTHESICS, Intravenous: propofol; DISEASES, Oncology: prostata neoplasia, PAIN, Postoperative; DIAGNOSIS EXAMS: prostata biopsy.

[Rev Bras Anestesiol 2010;60(5): 457-465] CElsevier Editora Ltda.

\section{INTRODUCTION}

Ultrasound-guided biopsy is a reference in the diagnosis of prostate tumors ${ }^{1-3}$. Successful detection of prostate cancer is related to the number of samples. On the other hand, the higher the number of samples greater the pain and discomfort ${ }^{1}$.

Pain during the procedure results from: the introduction of the transrectal transducer and penetration of the needle in the prostate capsule, which stimulates pain receptors located in this region ${ }^{4}$. The prostate is innervated by parasympathetic

Received from the Hospital das Clínicas da Faculdade de Medicina da Universidade de São Paulo-HCFMUSP.

1. PhD in Sciences from the Faculdade de Medicina da Universidade de São Paulo FMUSP, Anesthesiology Professor of Faculdade de Ciências Médicas de Santos-UNILUS. Supervising Physician of the Anesthesiology Department of the Instituto de Radiologia do HCFMUSP.

2. Anesthesiologist of the Anesthesiology Department of FMUSP

3. PhD in Sciences from USP, Supervising Physician of the Ultrasound Department of the Instituto de Radiologia do HCFMUSP

4. Associated Anesthesiology Professor of the Faculdade de Medicina da USP. TSA, Direc tor of the Anesthesiology Department of the Instituto Central do HCFMUSP

5. PhD in Sciences from USP. Intensive care specialist from AMIB, ICU Coordinator of the Anesthesiology Department of the Instituto Central do HCFMUSP

Submitted on March 25, 2010.

Approved on May 3, 2010.

Correspondence to:

Dr. Luiz Marcelo Sá Malbouisson

Divisão de Anestesia do ICHC Av. Enéas Carvalho de Aguiar, 255 - 8aad.

Cerqueira César

05403-900 - São Paulo, SP, Brazil

E-mail:malbouisson@hcnet.usp.br fibers that originate in the pelvic splanchnic nerves (S2 to S4) and sympathetic fibers of the inferior hypogastric nerves ${ }^{5}$. Approximately $96 \%$ of the patients report pain, with a score of 2 to 6 in the VAS, and $20 \%$ of those patients consider the pain to be severe ${ }^{1}$.

Due to the severity of the pain, an analgesia/anesthesia strategy is fundamental in prostate biopsies to decrease the discomfort for the patient and, consequently, increase the number of samples collected and the success of the procedure. Besides, many patients will need more than one intervention to collect biopsies in order to achieve a conclusive diagnosis ${ }^{6}$.

Several anesthetic techniques have been described and investigated in prostate biopsies, but a consensus in the literature regarding the most effective technique, such as conscious sedation with midazolam, general anesthesia with spontaneous ventilation with fentanyl and propofol, spinal anesthesia, and pudendal nerve block, is lacking ${ }^{6,7}$. Prostatic plexus block, performed by the radiologist, with the injection of several local anesthetics, is the analgesic technique used more often ${ }^{8-12}$. However, in this technique, the patient can undergo important physical and emotional discomfort 2,3,8.

Due to the discomfort related with the procedure, the use of sedation techniques, to promote patient comfort, is desirable. Sedation with propofol as the single drug or associated with prostatic plexus block and systemic opioids is an alternative frequently used in those cases. The objective of the present 
study was to compare the sedation of isolated propofol, associated with prostatic plexus block, and with systemic opioids regarding the quality of hypnosis, hemodynamic parameters, and postoperative pain.

\section{MATERIALS AND METHODS}

This study was approved by the Scientific Commission of the Instituto de Radiologia and Medical Ethics Commission of the Hospital das Clínicas da Faculdade de Medicina da Universidade de São Paulo. Forty five patients with classification I or II of the American Society of Anesthesiologists, and with indication of ultrasound-guided prostate biopsy, were randomly divided in three groups.

GROUP 1 (G1): Fifteen patients who received propofol, at an initial dose of 1 to $1.5 \mathrm{mg}^{\mathrm{kg}}{ }^{-1}$, with supplementary doses as needed;

GROUP 2 (G2): Fifteen patients who received propofol, at an initial dose of 1 to $1.5 \mathrm{mg}^{\mathrm{kg}}{ }^{-1}$, with supplementary doses of propofol as needed, associated with prostatic plexus block, performed by the ultrasonographist, with $40 \mathrm{mg}$ of $1 \%$ lidocaine without adrenaline.

GROUP 3 (G3): Fifteen patients who received propofol at an initial dose of 1 to $1.5 \mathrm{mg}^{\mathrm{kg}} \mathrm{kg}^{-1}$, with supplementary doses of propofol as needed, associated with $0.5 \mu \mathrm{g} \cdot \mathrm{kg}^{-1}$ of fentanyl.

This study was undertaken at the Instituto de Radiologia do Hospital das Clínicas da Faculdade de Medicina da Universidade de São Paulo; patients signed an informed consent and the presence of a companion was mandatory.

Patients were monitored with non-invasive blood pressure, continuous electrocardiogram, pulse oximetry, and bispectral index. Since all patients were from the outpatient clinic, preanesthetic medication was not used. During the procedure, patients remained on spontaneous ventilation. To maintain the peripheral oxygen saturation above 95\%, oxygen, 5 L.min. ${ }^{-1}$, was administered via a face mask.

The following parameters were evaluated:

Intraoperatively: Mean arterial, systolic, and diastolic pressures, heart rate, oxygen saturation, and bispectral index, were evaluated before the procedure, 5 minutes after beginning the procedure, and at the end. The total duration of the procedure and total dose of propofol were also recorded.

Postoperatively: Mean, systolic, and diastolic arterial pressures, heart rate, oxygen saturation, pain assessment using the verbal analogue scale, and the use of dypirone as rescue medication to treat postoperative pain. Those parameters were evaluated 15 , 30,45 , and 60 minutes after the end of the procedure.

After the procedure, patients were transferred to the postanesthetic recovery room, where they remained for 2 hours for observation of complications. Dypirone $2 \mathrm{~g} \mathrm{IV}$, was chosen as rescue medication in case of pain greater than 5 in the visual analogue scale.

The parameters were analyzed using the SPSS 16 (SPSS Inc., IL, USA) and Aabel 3 (Gigawiz Inc., USA) software. The
Kolmogorov-Smirnov test was used for the distribution of continuous or subtle variables. Anthropometric data were compared by one-way Analysis of Variance, for age and BMI. Weight, height, duration of the exam, total dose of propofol, ratio of propofol dose/weight, and the number of fragments were compared by the Kruskall-Wallis test. The ASA physical status distribution was compared among groups by the likelihood ratio test. Two-way Analysis of Variance for repetitive measurements was used to compare hemodynamic parameters, bispectral index, and oxygen saturation along time, followed by the Newmann-Keuls test when indicated for multiple comparisons. Pain levels according to the visual analogue scale were analyzed by the Friedman test, with intergroup comparison by the Kruskall-Wallis test, followed by the Dunn test in case of difference among the groups. The Chi-square test for tendencies was used to compare the use of dypirone. Values of $p$ lower than 0.05 were considered significant. Data are presented as mean \pm standard deviation, median (minimum-maximum), or absolute value (percentage). Charts are presented as mean \pm standard deviation or box diagram (maximum and minimum values, 25 interquartile, 75 interquartile, and median).

\section{RESULTS}

A significant difference was not observed among the three groups regarding anthropometric data (age, weight, height, body mass index), amount of propofol used, as well as examrelated variables: number of fragments and duration of the exam. Regarding the classification of physical status, patients in group 2 were more frequently classified as ASA I than in the other groups (Table I).

During the intraoperative period, the bispectral index had similar behavior in all three groups, with a fall 5 minutes after the beginning of the procedure and maintaining levels between 50 and 60 until the end of the observation period, as can be seen in Figure 1. Hemodynamic parameters, both in the intraoperative and postoperative periods, showed statistically similar behavior in all three groups. As shown in Figure 2, we observed that during the procedure a discrete fall in systolic, diastolic, and mean arterial pressures, but they recovered preoperative levels. A significant difference between the groups regarding heart rate and oxygen saturation was not observed (Figure 3).

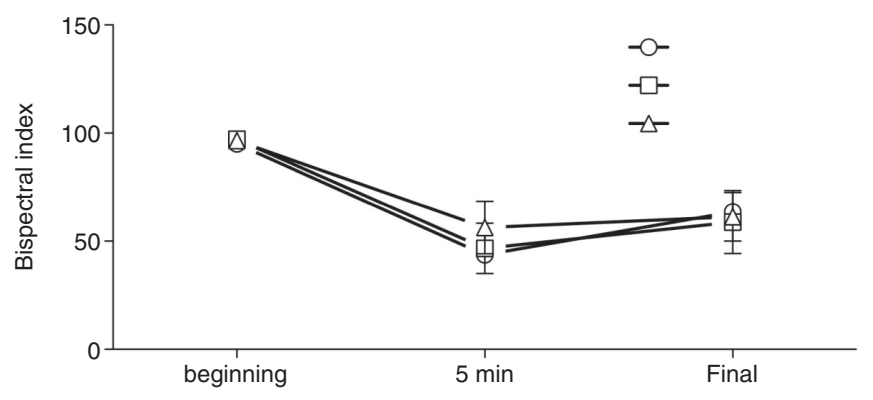

Figure 1. Bispectral Index in Patients in Groups 1 (open circles), 2 (open squares), and 3 (open triangle) along the study. 
Table I - Classification of Physical Status

\begin{tabular}{|c|c|c|c|c|}
\hline & \multicolumn{3}{|l|}{ GROUP } & \multirow[b]{2}{*}{$p$} \\
\hline & 1 & 2 & 3 & \\
\hline Age (years) & $64 \pm 9$ & $60 \pm 7$ & $66 \pm 7$ & 0.113 \\
\hline Height (m) & $1.7(1.6-1.8)$ & $1.7(1.6-1.9)$ & $1.7(1.6-1.8)$ & 0.854 \\
\hline $\mathrm{BMI}\left(\mathrm{kg} \cdot \mathrm{m}^{2}\right)$ & $28 \pm 4$ & $27 \pm 4$ & $27 \pm 2$ & 0.453 \\
\hline Duration of the exam (min) & $14(5-20)$ & $14(8-20)$ & $15(10-16)$ & 0.549 \\
\hline Propofol/weight (mg.kg-1) & $2.5(1.7-3.6)$ & $2.7(1.8-6.1)$ & $2.2(1.3-4.5)$ & 0.267 \\
\hline Fragments & $14(12-24)$ & $18(12-24)$ & $15(12-20)$ & 0.727 \\
\hline \multicolumn{5}{|l|}{ ASA classification (\%) } \\
\hline 1 & $0(0 \%)$ & $4(26.7 \%)$ & $2(13.3 \%)$ & 0.046 \\
\hline II & $15(100 \%)$ & $11(73,3 \%)$ & $13(86.7 \%)$ & \\
\hline
\end{tabular}

$\mathrm{BMI}$ - Body Mass Index. Data presented as mean \pm standard deviation, median (minimum-maximum), or absolute value (percentage).
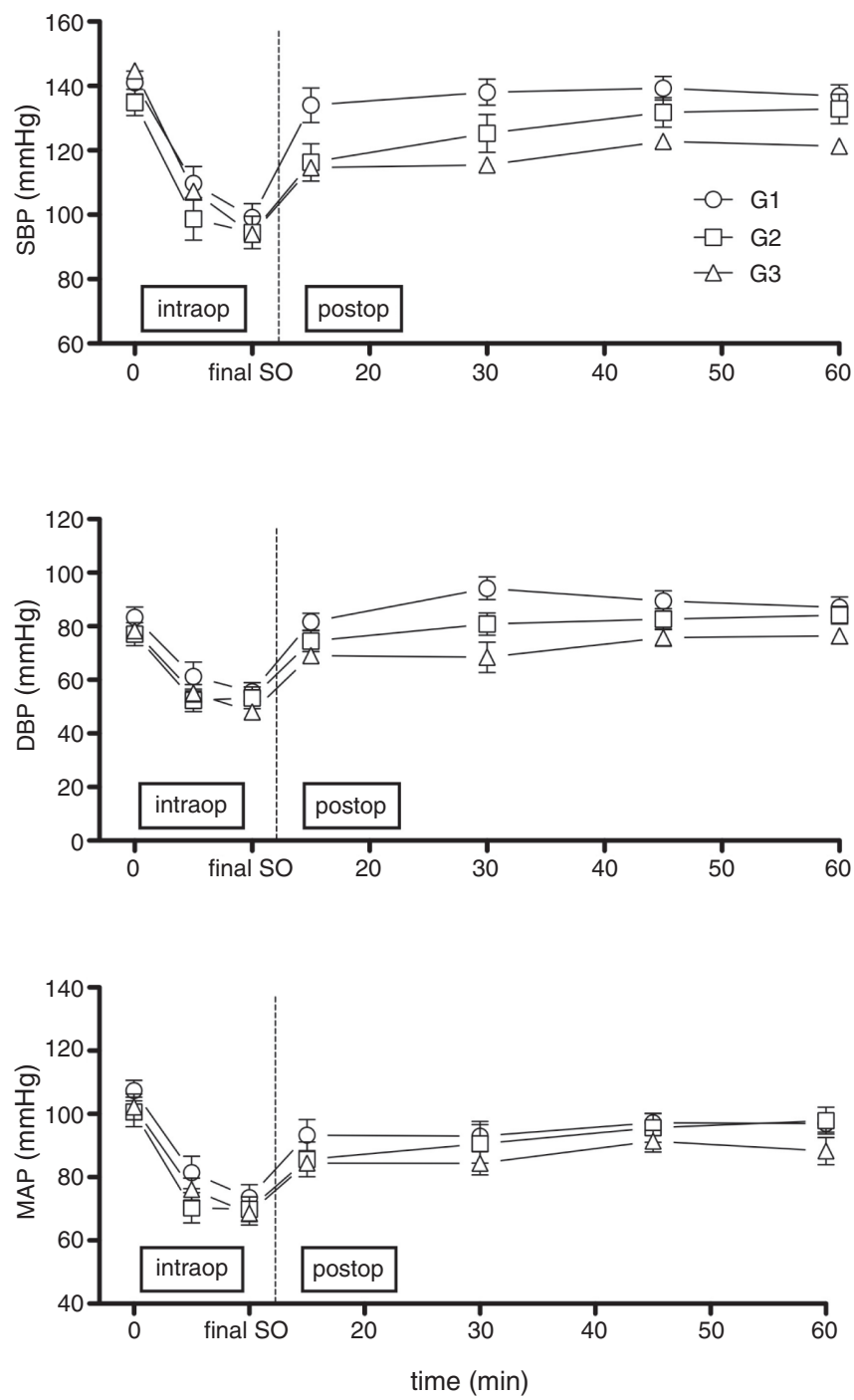

Figure 2. Systolic (upper panel), Diastolic (middle panel), and Mean (lower panel) Arterial Pressure in patients in groups 1 (open circles), 2 (open squares), and 3 (open triangles) along the study.
After the procedure, awakening from anesthesia was very fast in all three groups, although group 1 had a significantly higher number of patients with elevated pain score at 15 and 60 minutes when compared to groups 2 and 3, as can be observed in Figure 4. Te need of rescue medication for pain control was significantly higher in group 1 and progressive lower in groups 2 and 3 (Figure 5). In group 3, two cases of intraoperative respiratory depression were observed, which were reverted with positive pressure ventilation, without postoperative consequences.
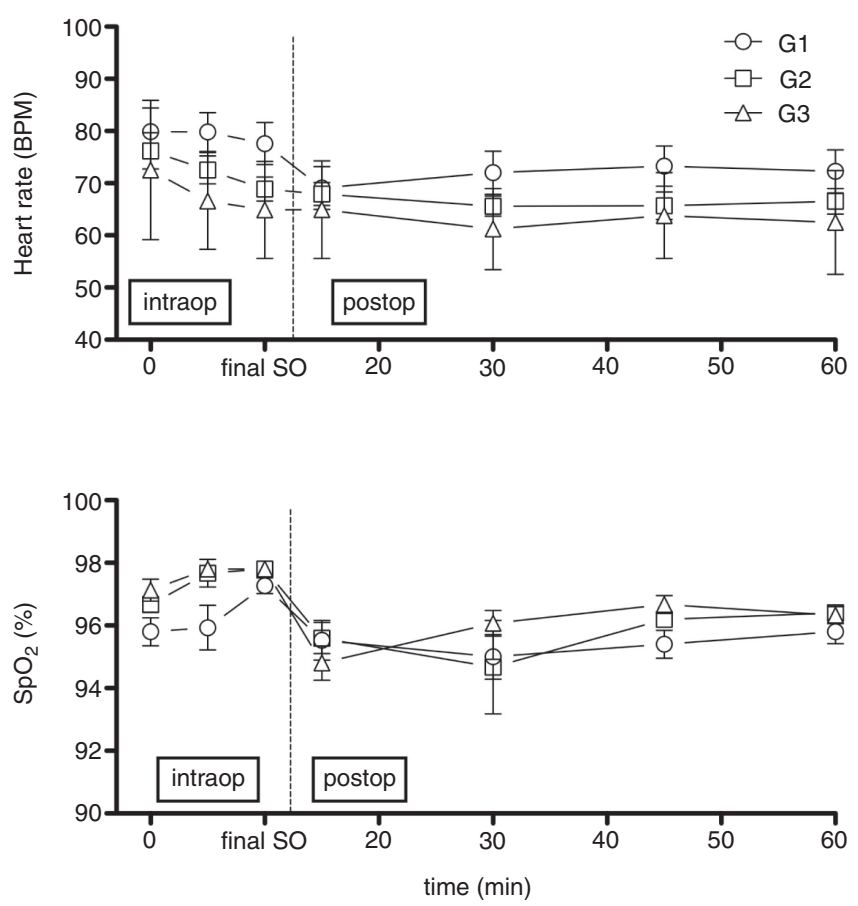

Figure 3. Heart Rate (upper panel) and Peripheral Oxygen Saturation (lower panel) in patients in groups 1 (open circles), 2 (open squares), and 3 (open triangles) along the study. 


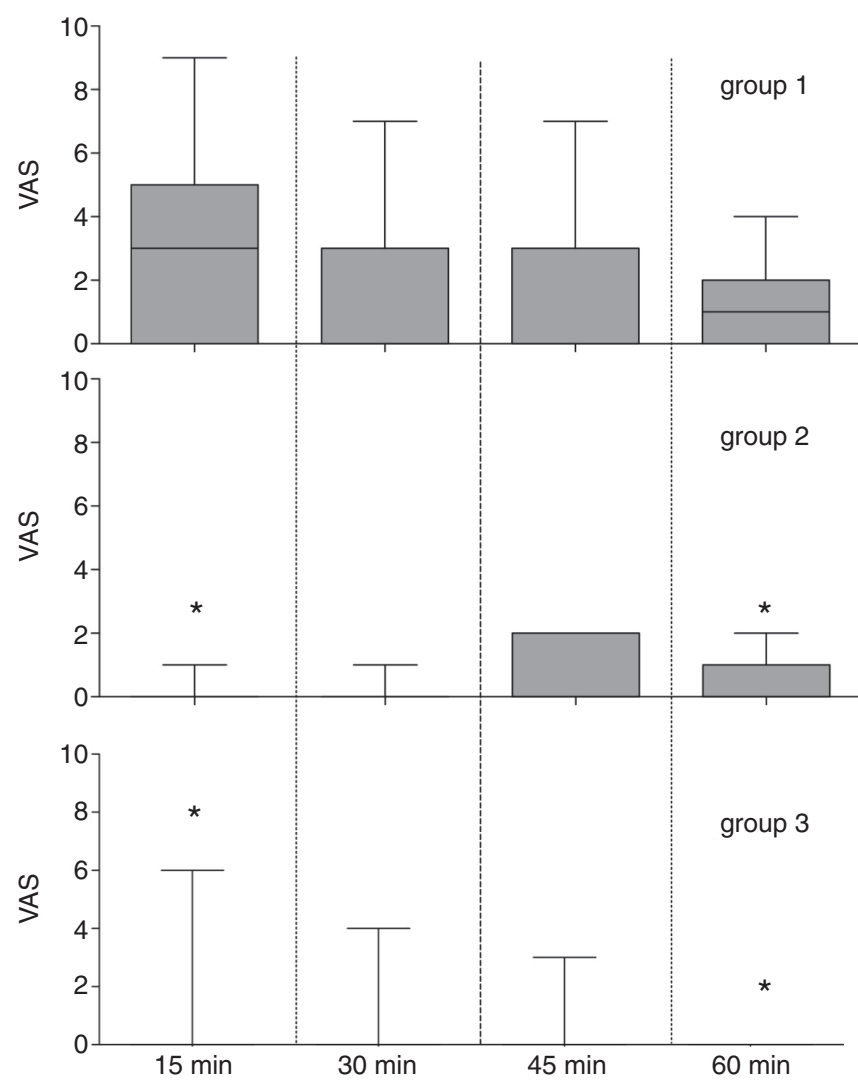

Figure 4. Box Diagram of Pain Scores, According to the VAS, in Patients in Groups 1 (upper panel), 2 (middle panel), and 3 (lower panel). ${ }^{*}$ means different from group 1.

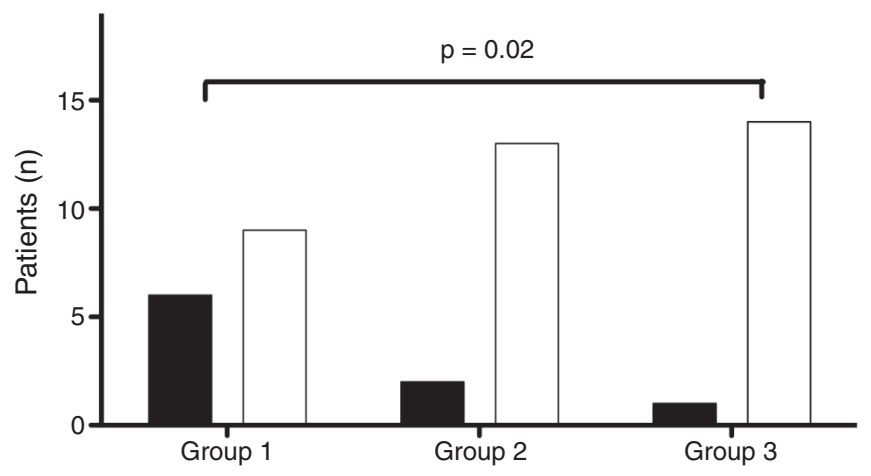

Figure 5. Use of Dypirone to Treat Postoperative Pain in Groups 1, 2, and 3 . The black bars represent patients who received dypirone, while open bars represent those who did not receive this medication.

\section{DISCUSSION}

Early diagnosis of prostate neoplasias is fundamental for a successful treatment. Biopsy is the reference in the diagnosis of prostate tumors. The higher the number of samples, the higher is the success of the procedure and the pain and discomfort reported by patients. Thus, realization of the procedure with the patient sedated allows a greater number of samples to be collected, which leads to a higher success rate and, consequently, the need of subsequent procedures.
However, a consensus in the literature regarding the best anesthetic technique does not exist. The present study compared three sedation techniques for ultrasound-guided prostate biopsy. Propofol was the hypnotic agent used in all three groups. The option for isolated propofol has been described in the literature as a technique associated with a high patient satisfaction index. Postoperative pain, in this case, is considered acceptable ${ }^{13}$. Parks et al. reported that this technique is safe and that the concentration at the site of action of the drug is around $1.5 \mu \mathrm{g} . \mathrm{L}^{-1}{ }^{14}$. Although hemodynamic parameters had shown a stable temporal behavior without statistically significant differences among the three groups, in patients who received isolated propofol, a tendency for increase in blood pressure and heart rate was observed. Even though the bispectral index was similar in all groups throughout the study, the severity of postoperative pain was significantly greater in the group of patients who received isolated propofol. Although the bispectral index was similar in all three groups along the study, the intensity of postoperative pain was significantly higher in patients who receive isolated propofol. Despite being considered a technique that promotes great patient satisfaction, according to the literature ${ }^{13}$, by reducing the discomfort secondary to the positioning of the ultrasound transducer, the fear of the patient regarding the procedure, and promoting a calm operative environment, it does not prevent postoperative pain. When those findings are compared to those of groups 2 and 3 , it is clear that the impact of the use of an analgesic technique, both systemic and regional, is very significant in the reduction of postoperative pain, representing a considerable advantage, since the patient will return home after the procedure. Several local anesthetics have been used in prostatic plexus block ${ }^{4,11,12,15}$. The duration of the local anesthetic could be related to postoperative discomfort. Lidocaine has been used in prostatic plexus block in our department. Despite the absence of significant differences in the severity of pain with lidocaine, a discrete increase in the scores of the visual analogue scale, which might mean the end of the effect of the local anesthetic used was observed, while in the fentanyl group, patients did not complaint of postoperative pain. This might indicate a discretely superior effect of the association propofolfentanyl in pain control when compared to group 2. However, this association is not devoid of risks, and two cases of intraoperative respiratory depression, possibly due to the interaction fentanylpropofol, that were reverted with positive pressure ventilation, were observed ${ }^{12}$. The anesthetic technique used did not alter the time of discharge, since all patients remained at least two hours in the post-anesthetic recovery room for observation of adverse events related to the procedure, such as bleeding.

Intercurrences suggestive of increased morbidity associated with the techniques evaluated, such as rectal bleeding, hematuria, or hematospermia, non-scheduled hospitalization, or infectious complications, were not observed. Changes in blood oxygenation or postoperative respiratory depression were also not observed.

To conclude, due to the pain and discomfort reported by patients, anesthesia in patients undergoing ultrasound-guided prostate biopsy is fundamentally important to promote comfort and increase the number of fragments collected. However, besides hypnosis, analgesia, regional or systemic, is also necessary for adequate control of postoperative pain. 
07. Obek C, Ozkan B, Tunc B et al. - Comparison of 3 different methods of anesthesia before transrectal prostate biopsy: a prospective randomized trial. J Urol, 2004;172:502-505.

08. Richman JM, Carter HB, Hanna MN et al. - Efficacy of periprostatic local anesthetic for prostate biopsy analgesia: a meta-analysis. Urology, 2006;67:1224-1228.

09. Montoliu Garcia A, Juan Escudero J, Ramos de Campos M et al. Prospective randomized study on the use of lidocaine local anesthesia in prostate biopsy. Arch Esp Urol, 2009;62:339-347.

10. Bingqian L, Peihuan L, Yudong $W$ et al. - Intraprostatic local anesthesia with periprostatic nerve block for transrectal ultrasound guided prostate biopsy. J Urol, 2009;182:479-483; discussion 483-474.

11. Akpinar $\mathrm{H}$, Tufek $\mathrm{I}$, Atug $\mathrm{F}$ et al. - Doppler ultrasonography-guided pelvic plexus block before systematic needle biopsy of the prostate: A prospective randomized study. Urology, 2009;74:267-271.

12. Yurdakul T, Taspinar B, Kilic $O$ et al. - Topical and long-acting local anesthetic for prostate biopsy: a prospective randomized placebocontrolled study. Urol Int, 2009;83:151-154.

13. Awsare NS, Green JA, Aldwinckle B et al. - The use of propofol sedation for transrectal ultrasonography-guided prostate biopsy is associated with high patient satisfaction and acceptability. Eur J Radiol, 2007;63:94-95.

14. Park JY, Park SJ, Choi SU et al. - Target-controlled propofol infusion for sedation in patients undergoing transrectal ultrasound-guided prostate biopsy. J Int Med Res, 2007;35:773-780.

15. Kandirali E, Ulukaradag E, Uysal B et al. - Is only perianal anesthesia with lidocaine-prilocaine cream sufficient to decrease the pain during transrectal ultrasound-guided prostate biopsy? A prospective randomized study. Urol Int, 2009;82:262-265.

Resumen: Barbosa RAG, Silva CD, Torniziello MYT, Cerri LMO, Carmona MJC, Malbouisson LMS - Estudio Comparativo entre Tres Técnicas de Anestesia General para Biopsia de Próstata Dirigida por Ultrasonido Transrectal.

Justificativa y objetivos: La biopsia de próstata dirigida por ultrasonido transrectal constituye una referencia en el diagnóstico de las neoplasias de la próstata. Mientras mayor es el número de muestras escogidas, mayores son el dolor y la incomodidad relatados por el paciente. El objetivo del estudio fue comparar tres técnicas anestésicas en ese grupo de pacientes.

Método: Fueron estudiados 45 pacientes divididos en tres grupos: 1- Propofol; 2- Propofol + Bloqueo de Plexo Prostático; 3- Propofol + Fentanil. Los pacientes fueron monitorizados con presión arterial no invasiva, electrocardioscopia continua, oximetría de pulso $\left(\mathrm{SpO}_{2}\right)$ e Índice Bispectral. No recibieron medicación preanestésica. Se evaluaron los parámetros hemodinámicos en el intra y postoperatorio, índice bispectral en el intraoperatorio, el dolor por la escala numérica verbal (ENV) en el postoperatorio inmediato y el uso de dipirona como tratamiento del dolor postoperatorio.

Resultados: No hubo diferencia significativa entre los tres grupos: en las variables antropométricas, cantidad de propofol, número de fragmentos y tiempo del examen. Los parámetros hemodinámicos y la $\mathrm{SpO}_{2}$ presentaron un comportamiento semejante en los tres grupos durante el estudio. En el grupo 1, el dolor evaluado por la ENV fue más elevado y hubo una mayor necesidad de aplicar la dipirona que en los otros grupos.

Conclusiones: La sedación con propofol aislado para la biopsia causa un mayor dolor e incomodidad en el postoperatorio que cuando se asocia al bloqueo del plexo prostático o al fentanil sistémico. Además de la hipnosis, se hace necesario realizar la analgesia intraoperatoria para garantizar la comodidad en el postoperatorio. 